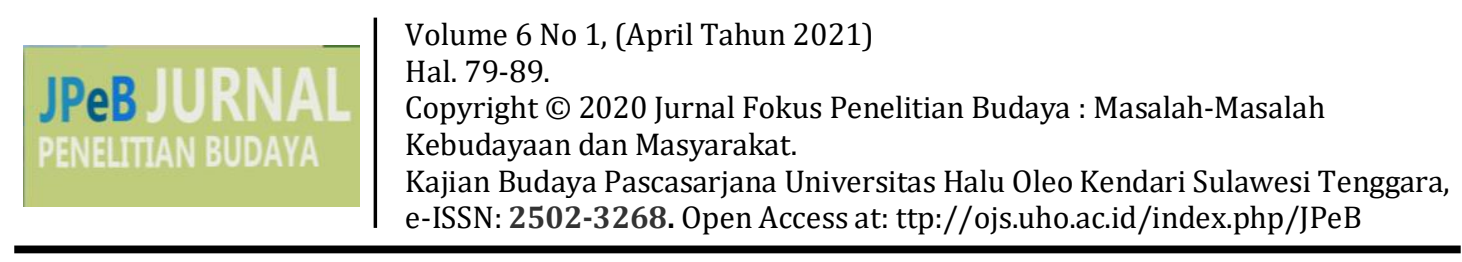

\title{
TRADISI MESAMBAKAY PADA KOMUNITAS ADAT TOLAKI- MEKONGGA (Studi Etnografi di Kabupaten Kolaka)
}

\author{
${ }^{1 *}$ Mohammad Diah, ${ }^{2)}$ Bahtiar, ${ }^{3)}$ La Ode Topo Jers \\ ${ }^{1}$ Program Studi Kajian Budaya Pascasarjana, Universitas Halu Oleo Kendari \\ ${ }^{2}$ Program Studi Kajian Budaya Pascasarjana, Universitas Halu Oleo Kendari \\ ${ }^{3}$ Jurusan Antropologi, Fakultas Budaya, Universitas Halu Oleo Kendari
}

\section{Corresnsponding Author: *Mohamad Diah (mohdiah24 @gmail.com)}

\begin{abstract}
Abstrak: Tujuan penelitian ini untuk (1) mengetahui dan menjelaskan proses mesambakay pada komunitas adat Tolaki-Mekongga, dan (2) menjelaskan makna simbolik mesambakay pada komunitas adat Tolaki-Mekongga di Kabupaten Kolaka. Penelitian ini menggunakan metode etnografi dengan pendekatan kualitatif. Teknik analisis data yang digunakan terdiri atas tiga tahapan, yakni reduksi data, penyajian data dan kesimpulan. Berdasarkan hasil penelitian ini menunjukkan bahwa: (1) Pelaksanaan ritual mesambakay pada komunitas adat Tolaki- Mekongga di Kabupaten Kolaka menggambarkan sebuah tradisi "memohon doa kepada tuhan" terhadap anak pertama (iliwua) yang berusia 40 hari hingga usia 2 tahun agar diberikan kekuatan, kesehatan serta kehidupan yang lebih baik. Apabila anak pertama telah dimesambakay maka anak kedua dan seterusnya sudah otomatis termaksud dalam ritual mesambakay sehingga tidak perlu untuk dilaksanakan lagi. (2) Makna simbolik mesambakay pada komunitas adat Tolaki-Mekongga di Kabupaten Kolaka menunjukkan sebuah interaksi antarsesama makhluk Tuhan. Selain itu, bahan dan alat mesambakay juga memiliki makna simbolik, seperti bambu (kowuna), tempat makanan (siwole), ikat kepala (kinawo), daun-daunan (tawa), tempurung kelapa (ullo), dan sepasang ayam (omanu). Dengan demikian, dapat disimpulkan bahwa tradisi mesambakayp pada komunitas adat Tolaki-Mekongga (Studi Etnografi Pada Kecamatan Wundulako Kabupaten Kolaka) terus menerus dilakukan serta menjadi salah satu tradisi dalam memperkokoh tali silaturahmi antarmasyarakat di Kabupaten Kolaka.
\end{abstract}

\section{Kata-kata Kunci: Tradisi Mesambakay, Komunitas adat Tolaki- Mekongga}

\begin{abstract}
The objectives of this research are to: (1) know and explain the mesambakay process in Tolaki-Mekongga customary community in Kolaka Regency, (2) explain the symbolic meaning of mesambakay in the Tolaki-Mekongga customary community in Kolaka Regency. This research method uses ethnographic method with a qualitative approach. The data analysis technique used in this study consists of three stages carried out simultaneously, namely data reduction, data presentation and conclusion. The results of this study indicate that: (1) The process of implementing the mesambakay ritual in the Tolaki-Mekongga customary community in Kolaka District depicts a tradition of "asking God for prayer" for the first child (iliwua) aged 40 days to the age of 2 years to be given strength, health and a better
\end{abstract}


life. If mesambakay has been done for the first child, the next children are believed have been done by mesambakay ritual. (2) The symbolic meaning of mesambakay in the Tolaki-Mekongga customary community in Kolaka Regency shows the existence of interaction among creatures. Besides, the tools and materials used have also symbolic meaning, such as bamboo (kowuna), a food container (siwole), a headband (kinawo), leaves (laughter), a coconut shell (ullo), and a pair of chickens (omanu). Thus, it can be concluded that the Mesambakay tradition in the Tolaki-Mekongga indigenous community (Ethnographic Study in Wundulako Subdistrict, Kolaka Regency) is continuously carried out and has become one of the traditions in strengthening the ties of friendship between communities in Kolaka Regency.

Key words: Mesambakay tradition, Tolaki-Mekongga indigenous community

\section{PENDAHULUAN}

Keberagaman budaya yang dimiliki setiap daerah di Indonesia merupakan sumber pengetahuan sebagai bentuk peradaban di berbagai aspek kehidupan manusia. Budaya lokal sebagai sumber pengetahuan dianggap penting karena menyangkut hidup dan kehidupan masyarakat pemiliknya, misalnya kearifan lokal (local wisdom), sistem nilai, pengetahuan tradisional, (local knowledge), sejarah, hukum, adat, pengobatan, sistem kepercayaan dan religi, astrologi, dan berbagai hasil seni. Warisan budaya bangsa adalah cermin tingginya peradaban bangsa. Dan salah satu ciri bangsa besar dan maju adalah bangsa yang mampu menghargai dan melestarikan warisan budaya nenek moyang mereka. Semakin banyak warisan budaya masa lampau yang bisa digali dan dilestarikan, maka sudah semestinyalah peninggalan budaya tersebut semakin dihargai.

$$
\text { Menurut Koentjaraningrat }
$$

(2009: 88), wujud kebudayaan dibedakan menjadi tiga: ideas (ide), activities (aktivitas/tindakan, dan artifacts (hasil karya fisik). Ketiga wujud kebuyadaan tersebut dalam kenyataan kehidupan masyarakat antara satu dengan yang lainnya tidak dapat dipisahkan, kebudayaan idea mengatur masyarakat tentu tak terpisah satu dengan yang lain, kebudayaan idea mengatur dan memberi arah kepada tindakan dan karya manusia. Apabila dilihat dari proses yang terjadi, maka tahap gagasan merupakan awal proses rancangan artefak. Proses diawali oleh gagasan melalui tindakan hingga akhirnya terbentuk hasil karya fisik, sehingga sedikit perubahan yang terjadi pada tahap gagasan, berarti akan terjadi perubahan pula pada karya akhirnya.

Lebih lanjut, nilai-nilai budaya sangat berperan dalam berbagai kehidupan manusia. Semua nilai yang terdapat dalam budaya tersebut dapat berkonstribusi positif bagi kehidupan masyarakat. Jika nilai-nilai budaya tersebut dintegrasikan kedalam masing-masing individu maka dapat menciptakan kehidupan yang harmonis, nyaman, dan sejahtera, bahkan pengembangan daerah melalui aspek pengintegrasian nilai-nilai budaya sangat penting karena daerah dan masyarakatnya tidak dapat dilepaskan dari aspek budaya. Pengembangan aspek nilai-nilai budaya dalam pembangunan daerah mampu memberikan kontribusi yang cukup besar.

Menurut Geertz (1992: 34) bahwa betapa sulitnya mengetahui 
kebudayaan, dalam hal ini yang dimaksud adalah berkenaan dengan tanda-tanda dari sebuah masyarakat dan warganya, apabila dengan cara menafsirkan makna mampu memberikan kontribusi yang cukup besar maka nilainilai kebudayaan ada pada masyarakat tertentu. Selanjutnya Geertz memakai dasar berpijak bahwa kebudayaan bukalanlah sesuatu yang ada di dalam benak atau isi kepala seseorang, maka kalau bicara mengenai ideologi atau politik kebudayaan, hal ini adalah sejauh ditafsirkan dari pengamatannya terhadap simbo-simbol yang saling berinteraksi dan makna-makna yang terkait yang saling berpengaruh dalam kehidupan umum.

Eksistensi sebuah budaya lokal dalam masyarakat tertentu tidak hanya dimaksudkan untuk membantu mewujudkan harmoni hidup bersama pada saat terbentuknya saja, tetapi dapat dipakai sebagai perangkat kehidupan sampai ke masa yang akan datang. Nilai-nilai tersebut dapat membentuk karakter masyarakat pemilik kebudayaan. Nilai-nilai itu akan terinternalisasi, baik ke dalam pribadipribadi maupun sistem sosial atau kelembagaan sosial masyarakat pendukung tradisi.

Hal paling mendasar dalam pembangunan karakter adalah bagaimana menggali nilai-nilai budaya yang ada di wilayah kerja terlebih dahulu. Berbagai penggalian nilai budaya nantinya akan diklasifikasikan untuk memastikan nilai budaya yang positif untuk dikembangkan menjadi bahan ajar dalam pembangunan karakter. Selain itu, nilai-nilai tersebut dapat dikembangkan dan dilestarikan selanjutnya diajarkan untuk generasi muda untuk dipahami.

Berdasarkan kompleksitas kandungan budaya lokal, maka pengkajian budaya lokal, khususnya pada aspek nilai-nilainya sangat penting, karena dapat menjadi alat untuk memahami jati diri bangsa sekaligus sebagai alat dalam memahami proses pewarisan budaya antar generasi. Walaupun demikian, pengkajian aspek budaya lokal khususnya di Sulawesi Tenggara lebih banyak fokus pada bentuk, nilai, dan fungsi, tanpa melihat lebih jauh pada implikasi dan praktik terhadap nilai- nilai tersebut. Kondisi ini mengarah pada terkikisnya nilai-nilai budaya masyarakat secara umum. Padahal, jika dikaji secara mendalam dan komprehensif, nilai-nilai sosial budaya masyarakat di Sulawesi Tenggara memiliki banyak manfaat dan nuansa inovatif. Nilai-nilai budaya tersebut dapat diketahui melalui berbagai jalan, diantaranya adalah melalui penelusuran bentuk dan makna atau tradisi masyarakat.

Salah satu kelompok masyarakat di Sulawesi Tenggara adalah komunitas adat Tolaki- Mekongga yang mendiami Kabupaten Kolaka (Kendari Pos, 2010). Masyarakat tersebut memiliki berbagai macam budaya atau tradisi, diantaranya adalah mesambakay. Pada umumnya mesambakay merupakan penyambutan kelahiran bayi pertama. Ritual tersebut pada awalnya dilakukan di zaman pemerintahan Raja Mekongga ke-5, yaitu Sangia Lamba Lambasa terhadap putranya yang bernama Sangia Lombo-Lombo. Istilah mesambakay berasal dari komunitas adat TolakiMekongga, yang terdiri atas dua kata, yaitu mesomba artinya bermohon kepada yang maha kuasa dan sambakai artinya 'anak keturunan'. Jadi, mesambakay artinya, permohonan kepada Tuhan agar anaknya itu diberi kekuatan, keselamatan, dan kebahagiaan hidup 
(Anwar, 2009: 13).

Tradisi Mesambakay ini termasuk salah satu tradisi masyarakat komunitas adat Tolaki-Mekongga yang dilaksanakan secara besar- besaran, ramai dan penuh hikmat sakral sehingga diharapkan masyarakat ikut terlibat didalamnya termasuk seluruh utusan yang mewakili negerinya (daerah) masing-masing dari pihak kerajaan bahkan tokoh adat, masyarakat, agamawan, pemerintah sipil maupun militer akan larut bersama dalam pesta pelaksanaan mesambakay (Wawancara, Bapak Gufira, 2020).

Menurut kepercayaan leluhur pada komunitas adat TolakiMekongga, setiap melahirkan anak pertama, keluarga tersebut harus menjalankan tradisi mesambakay. Apabila itu tidak dilaksanakan, keluarga tersebut diyakini akan mendapatkan banyak masalah, bencana, penyakit, dan tidak bahagia. Mesambakay merupakan syukuran anak pertama yang baru lahir, yang biasa dilakukan ketika anak tersebut baru berusia 40 hari hingga berumur 2 tahun. mesambakay memiliki banyak makna simbolik, diantaranya bermakna sebagai rasa syukur, kerendahan hati, keteladanan, dan ketaatan (Wawancara Bapak Gufira,

2020)

Berdasarkan hasil observasi dan penelitian ternyata pelaksanaan tradisi mesambakay masih dilakukan di daerah Kabupaten Kolaka yaitu pada suku Tolaki-Mekongga yang merupakan ciri khas tradisi lokal masyarakat di Kabupaten Kolaka dan penyelenggaraan mesambakay memiliki beberapa syarat diantaranya adanya mbuakoy (orang yang pandai baca mantra), umo rapi (orang yang akan berteriak), dan seorang remaja yang akan memangku anak dalam pelaksanaan mesambakay.

Berdasarkan keterangan di atas, mesambakay merupakan salah satu ritual yang sangat penting, khususnya bagi komunitas adat Tolaki-Mekongga di Kabupaten Kolaka. Mengingat pembahasan dan literatur tentang mesambakay sangat sedikit, maka penggambaran mesambakay tersebut sangat diperlukan. Oleh karena itu, penelitian ini sangat penting untuk dilaksanakan, khususnya terkait dengan proses dan makna ritual mesambakay yang belum dikaji sebelumnya secara komprehensif.

Terkait dengan penelitian ini, La Aso dan Taembo (2016) melakukan penelitian mengenai ritual kasambu pada masyarakat etnik Muna di Kabupaten Muna Provinsi Sulawesi Tenggara. Dalam penelitian La Aso, dijelaskan bahwa ritual kasambu merupakan salah satu budaya lokal pada etnik Muna yang dilakukan oleh seorang istri untuk kehamilan pertamanya yang berumur sekitar 7 sampai 8 bulan. Tujuannya adalah untuk meminta keselamatan bagi istri tersebut dan bayinya yang masih dalam kandungan. Adapun, pelaksanaan ritual mesambakai pada penelitian ini lebih bertujuan untuk memberikan keselamatan, kesehatan, dan kekuatan kepada anak pertama yang baru lahir. Walaupun demikian, ritual mesambakai dan kasambu memiliki kemiripan dalam hal mengharapkan kesehatan terhadap anak pertama. Berdasarkan penelusuran hasil penelitian terdahulu belum ditemukan penelitian tentang mesambakay pada komunitas adat Tolaki-Mekongga.

\section{METODE PENELITIAN}

Penelitian ini dirancang dengan menggunakan pendekatan kualitatif. 
Penelitian ini termasuk penelitian lapangan, dengan studi etnografi atau fenomena yang ada di Kabupaten Kolaka. Penelitian lapangan merupakan ciri khas Antropologi Budaya (Spradley, 1997: 3). Etnografi sebagai metode penelitian yang menghasilkan data deskripsi berupa kata-kata tertulis atau lisan dari orang- orang dan perilaku yang dapat diamati. Spradley (1997: 22) menjelaskan bahwa metode kualitatif adalah salah satu prosedur penelitian yang menghasilkan data deskriptif. Selain itu, Wardiyanta (2006: 5) mengatakan bahwa penelitian deskriptif adalah penelitian yang bertujuan membuat deskripsi atas suatu fenomena sosial alam secara sistematis, faktual dan akurat.

Data penelitian ini dibagi atas data primer dan data sekunder. Data primer adalah hasil pengamatan langsung dan hasil wawancara mendalam dengan informan di lapangan. Data primer berasal dari jawaban informan atas daftar pertanyaan yang dibuat oleh peneliti. Adapun data sekunder berupa hasil penelitian sebelumnya, naskah, dokumen, dan teks lainnya. Teknik pengumpulan data yang digunakan dalam penelitian ini adalah observasi, wawancara, dan dokumentasi. Teknik analisis data yang digunakan terdiri atas tiga tahapan, yakni reduksi data, penyajian data dan kesimpulan.

\section{HASIL DAN PEMBAHASAN \\ Proses Pelaksanaan Mesambakay pada Komunitas adat Tolaki- Mekongga di Kabupaten Kolaka}

\footnotetext{
Ritual adat mesambakay merupakan salah satu tradisi daur hidup (life cycle) yang dilaksanakan oleh masyarakat Kabupaten Kolaka. Secara etimologi istilah mesambakay berasal
}

dari bahasa Mekongga, yang terdiri dari dua kata "mesomba" yang berarti memohon kepada yang maha kuasa dalam hal ini Allah SWT, dan sambakay yang artinya anak keturunan (Anwar, 2009: 13). Namun dalam hal ini ritual mesambakay hanya dilakukan oleh anak pertama saja dan anak kedua dan seterusnya sudah otomatis termaksud dalam ritual mesambakay sehingga tidak perlu untuk dilaksanakan lagi. Hal ini berdasarkan informasi dari bapak Gufira (58 tahun) seorang informan menyatakan bahwa:

"Anak pertama memang harus melakukan proses adat mesambakay khususnya dari keturunan komunitas adat Tolaki- Mekongga baik perempuan maupun laki-laki harusnya melakukan ritual mesambakay, sedangkan orang dari luar saja misalnya jawa atau bugis yang menikah dengan orang Mekongga mereka juga tetap melakukan ritual mesambakay karna mereka mengerti dan tahu untuk menghargai dan tetap melestarikan budaya lokal masyarakat setempat", (Wawancara 3 Mei 2020).

Praktiknya, ritual mesambakay juga menggambarkan sebuah tradisi "memohon doa kepada tuhan" yang lazimnya dilakukan oleh masyarakat komunitas adat Tolaki- lainnya. Tradisi mesambakay ini berarti sebuah ritual yang dilakukan terhadap anak pertama (iliwua) yang berusia 40 hari hingga usia 2 (dua) tahun berdasarkan hasil penelusuran dilapangan.Berikut keterangan informan tentang mesambakay di Kabupaten Kolaka, melalui wawancara dengan bapak Firman Guro (77 tahun) menyatakan bahwa:

"Tradisi mesambakay hanya dilakukan pada anak pertama saja, 
maksudnya untuk meminta doa kepada yang maha kuasa agar anak tersebut diberikan kekuatan serta kesehatan dalam kehidupannya, ritual ini terus dilakukan di sebagai warisan budaya leluhur yang tidak dapat ditinggalkan" (Wawancara 5 Mei 2020).

Berdasarkan keterangan tersebut, maka dapat dipahami bahwa tradisi mesambakay merupakan tata cara atau kebiasaan komunitas adat TolakiMekongga dalam meminta doa kepada yang maha kuasa dengan melakukan ritual mesambakay, selain itu ritual tersebut terus menerus dilakukan khususnya di Kabupaten Kolaka.

Masyarakat Mekongga menganggap tradisi, karena setiap kelahiran anak pertama dari keluarga yang telah atau baru menikah, selalu diadakan ritual mesambakay. Hal demikian sesuai dengan pernyataan bapak Yunus Sulaeman (62 tahun) melalui wawancara menyatakan bahwa:

"Mano teaso mbihapo tiolu ato pobasa kee anadalo", Artinya: "Sekalipun hanya telur satu biji asalkan mesambakay harus tetap dilaksanakan", (Wawancara 3 Mei 2020).

\section{Berdasarkan keterangan}

tersebut, maka dapat diketahui bahwa begitu pentingnya ritual mesambakay harus dilakukan oleh komunitas adat Tolaki- Mekongga, sekalipun hanya dilakukan dengan persiapan telur satu biji yang penting ritual mesambakay harus tetap dilakukan.

Secara historis, tradisi mesambakay sebenarnya telah dikenal oleh masyarakat Mekongga sebelum (pra) masuknya ajaran Islam di Wilayah Mekongga yaitu pada awalnya dilakukan di zaman pemerintahan Raja Mekongga ke-5, yaitu Sangia Lamba Lambasa terhadap putranya yang bernama Sangia Lombo-Lombo. Berikut kutipan wawancara bersama bapak Gufira (58 tahun) bahwa:

"Tradisi mesambakay ini sudah lama sekali dilakukan masyarakat sejak zaman Kerajaan Mekongga tradisi ini dilakukan turun temurun sampai sekarang masih tetap dilakukan, ritual ini tetap dipertahankan oleh masyarakat walaupun ini sudah jaman modern malah lebih bagus lagi supaya masyarakat semua tau bahwa di Kabupaten Kolaka itu ada namanya tradisi ritual mesambakay", (Wawancara 3 Mei 2020).

Meskipun ajaran Islam masuk di wilayah tersebut ritual mesambakay masih tetap dilaksanakan oleh masyarakat, namun pelaksanaannya sudah dipadukan dengan ajaran Islam. Dengan demikian, dipahami bahwa ritual mesambakay merupakan tradisi yang telah mengakar dalam kehidupan dan hingga kini masih ditaati, dipatuhi dan dilaksanakan oleh sebagian masyarakat Mekongga. Dalam pandangan Geertz bahwa biasanya sesuatu yang sakral adakalanya tidak berbentuk pada benda-benda yang kongret seperti dewa-dewa, malaikat, roh-roh dan lain-lain. Yang sakral pada umumnya dijadikan sebagai objek atau sarana penyembahan dari upacaraupacara keagamaan dan diabadikan dalam ajaran kepercayaan. Dalam ajaran kepercayaan inilah kemudian muncul adanya - yang diatur oleh aturan tertentu sesuai kepercayaan dan keyakinan agama manusia, atau adat tertentu suatu masyarakat.

Fakta hasil observasi menunjukkan bahwa ritual mesambakay masih tetap dilakukan oleh masyarakat Mekongga khususnya di Kabupaten 
Kolaka, karena mereka menganggap suatu tradisi yang tidak dapat ditinggalkan dan sebagai warisan budaya yang ditransmisi dari generasi ke generasi.

\section{Makna Simbolik Mesambakay pada Komunitas Adat Tolaki-Mekongga di Kabupaten Kolaka}

Tradisi ritual mesambakay merupakan salah satu tradisi masyarakat Mekongga yang berkaitan dengan system religi dan kepercayaan dalam kehidupan. Bagi masyarakat Mekongga, tradisi mesambakay melegitimasi bahwa anak yang di doakan akan memiliki kehidupan yang baik serta memiliki kekuatan dan kesehatan dalam mengarungi kehidupan. Berdasarkan prosesi ritual mesambakay makna simbolik dari ritual mesambakay ini dapat diketahui berdasarkan studi etnografi masyararakat di Kabupaten Kolaka sehingga Mesambakay ini bermakna dalam mempererat hubungan silaturahmi antara anak dan keluarga. Ritual mesambakay ini merupakan sarana komunikasi dalam menjalin hubungan dengan keluarga.

Hubungan saat anak sudah memasuki tahap perkembangan dan mulai terbina melalui ritual mesambakay. Anak mulai memiliki rasa ingin mempunyai teman untuk membina hubungan itu sendiri dan tampa kita sadari anak akan merekam semua apa yang terjadi dalam lingkungannya mereka akan mulai menirunya. Selain itu, hubungan yang baik dengan orang lain juga terbangun melalui ritual ini. Adanya keterlibatan sosial dan juga kerja tim sangat penting karena merupakan satu hal yang saling berkaitan. Melalui interaksi sosial atau berhubungan langsung ke lingkungan sosial itu maka harus siap dalam hal berkerja sama. Dalam hal ini, suatu lingkungan rumah dengan tentangga sekitar dan warga kampung yang mengadakan ritual mesambakay, otomatis saat sudah terjun dalam keterlibatan sosial pasti akan ikut serta dalam kerja bakti karena itu adalah kerja tim antar tentangga yang ada di lingkungan itu.

Selain itu, simbol-simbol dari ritual mesambakay ini dapat di lihat dari beberapa alat dan bahan yang digunakan dalam ritual mesambakay tersebut. Bahan-bahan yang digunakan dalam ritual mesambakay memiliki makna tersendiri bagi anak atau bayi yang di doakan dari kegiatan ritual mesambakay.

Ritual mesambakay di Kabupaten Kolaka sudah ada dan tetap dilestarikan oleh masyarakat itu sendiri. Keberadaan ritual mesambakay sudah ada sejak zaman kerajaan Mekongga. Kehidupan sosial budaya dibentuk oleh masyarakat sebagai pendukung dari kebudayaan hingga saat ini.

Dalam hal ini, masyarakat diartikan sebagai kelompok manusia yang telah cukup lama hidup dan bekerjasama, sehingga mereka ini dapat mengorganisasikan dirinya berpikir tentang dirinya dalam satu kesatuan sosial maupun budaya dengan batas-batas tertentu. Dengan demikian, masyarakat itu timbul dari setiap kumpulan individu, yang telah lama hidup dan bekerjasama dalam waktu yang cukup lama.

Melalui interaksi sosial terjadi kerja sama yang semakin mempererat interaksi sosial yang pokok. Hal ini dapat dijumpai pada berbagai kelompok manusia, dimulai dari masa kanak-kanak sampai dewasa. Selain itu, orientasi orang perorangan terhadap kelompoknya (in group) atau kelompok lainnya (out group) juga dapat 
mengantarkan pada kerjasama. Kerja sama akan bertambah kuat jika ada ancaman atau bahaya dari luar.

Hal ini dapat ditegaskan dalam wawancara dengan informan bapak Gufira (58 tahun) mengatakan sebagai berikut.

"Pelaksanaan ritual adat mesambakay ini memiliki makna yang cukup baik terutama dalam memohon doa kepada yang maha kuasa agar kita senantiasa terhindar oleh musibah terutama bagi anakanak, kita tidak lupa pada maha pencipta agar diberikan kekuatan serta kehidupan yang lebih baik, selain itu melalui ritual mesambakay ini dapat mempererat tali silaturahmi antara keluarga, terjadi interaksi sosial jadi banyak hal yang bisa dipetik dalam pelaksanaan ritual tersebut" (Wawancara 20 Mei 2020).

Lebih jauh, manusia berkomunikasi dan senantiasa saling membutuhkan satu dengan yang lainnya. Setiap manusia mempunyai kepentingan baik sama maupun berbeda, demikian pula kebutuhan dan juga hasrat atau keinginan, namun pada kenyataannya semua kebutuhan itu tidak dapat dipenuhinya seorang diri.

Menurut Weber (1957: 32) bahwa perilaku manusia yang merupakan pelilaku sosial harus mempunyai tujuan tertentu yang terwujud dengan jelas. Artinya perilaku itu harus mempunyai arti bagi pihak-pihak yang terlibat yang kemudian berorientasi terhadap perilaku yang sama dengan pihak lain.

Hal tersebut ditegaskan dalam wawancara dengan informan bapak Gufira (58 tahun) mengatakan sebagai berikut.

"Pelaksanaan ritual adat mesambakay ini memiliki arti penting dalam membina hubungan antara keluarga atau masyarakat, selain kita mendoakan agar anak kita diberikan kekuatan dan kesehatan dalam kehidupannya, diharapkan juga kita bisa lebih mempererat hubungan silaturahmi antar warga dan pemerintah agar kehidupan bermasyarakat itu muncul rasa persaudaraan" (Wawancara 20 Mei 2020).

Keterangan informan di atas menegaskan bahwa manusia tidak dapat hidup tanpa bantuan orang lain untuk senantiasa bertahan hidup dan untuk hidup sebagai manusia. Makna simbolik yang terdapat dalam tradisi mesambakay yang ada di Kabupaten Kolaka, diharapkan lebih mempererat hubungan silaturahmi antar masyarakat serta masyarakat dan pemerintah sehingga kehidupan bermasyarakat itu menghasilkan rasa persaudaraan, dan membuat masyarakat tidak memandang atau membendakan satu sama lain dan memandang dari stratifikasi soasialnya saja. Akan tetapi dari cara berinteraksi sosial maupun budaya bermasyarakat. Dengan demikian hidup bermasyarakat akan saling memiliki rasa solidaritas sosial yang tinggi khususnya di tanah mekongga Kabupaten Kolaka. Ritual adat Mesambakay merupakan salah satu tradisi yang dilaksanakan oleh masyarakat Kabupaten Kolaka. Secara etimologi istilah Mesambakay berasal dari bahasa Mekongga, yang terdiri dari dua kata "mesomba" yang berarti memohon kepada yang maha kuasa dalam hal ini Allah SWT, dan sambakay yang artinya anak keturunan.

Hal ini sesuai yang dikatakan Geertz (1992: 32) bahwa ritual atau 
tradisi bisa disebut juga dengan budaya karena pada dasarnya semua itu adalah produk dari manusia. Apabila berbicara tentang kebudayaan maka kita akan langsung berhadapan dengan makna dan arti tentang budaya itu sendiri. Seiring dengan berjalannya waktu, banyak para ilmuwan yang sudah menfokuskan kajiannya untuk mempelajari fenomena kebudayaan yang ada di masyarakat.

Ritual mesambakay hanya dilakukan oleh anak pertama saja dan anak kedua dan seterusnya sudah otomatis termaksud dalam ritual mesambakay sehingga tidak perlu untuk dilaksanakan lagi. Sebagaimana dalam kutipan wawancara yang dilakukan oleh bapak Gufira (58 tahun) mengatakan sebagai berikut:

"Anak pertama memang harus melakukan proses adat mesambakay khususnya dari keturunan Mekongga baik perempuan maupun laki-laki harusnya melakukan ritual mesambakay, sedangkan orang dari luar saja misalnya jawa atau bugis yang menikah dengan orang Mekongga mereka juga tetap melakukan ritual mesambakay karna mereka mengerti dan tahu untuk menghargai dan tetap melestarikan budaya lokal masyarakat setempat". (Wawancara 3 Mei 2020).

Ritual mesambakay juga menggambarkan sebuah tradisi "memohon doa kepada tuhan" yang lazimnya dilakukan oleh masyarakat komunitas adat Tolaki- lainnya. Tradisi mesambakay ini berarti sebuah ritual yang dilakukan terhadap anak pertama (iliwua) yang berusia 40 hari hingga usia 2 tahun.

Menurut Geertz (1992: 26) menyatakan bahwa agama, sebagai sistem kebudayaan, tidak terpisah dengan masyarakat. Agama tidak hanya seperangkat nilai yang tempatnya diluar manusia tetapi agama juga merupakan sistem pengetahuan dan sistem simbol yang mungkin terjadinya pemaknaan.

Ritual mesambakay yang dilakukan di Kabupaten Kolaka bahwa kepercayaan ini muncul karena adanya keyakinan serta menjadi kebiasaan dalam suatu masyarakat yang diteruskan secara turun termurun dan telah menjadi aturan dalam komunitas adat Tolaki- Mekongga bahwa ritual tersebut merupakan khasanah budaya yang diwariskan oleh leluhur dan diteruskan oleh generasi berikutnya.

Aturan-aturan inilah yang kemudian mengikat mereka, sehingga sesuai keyakinan suatu masyarakat jika ingin selamat dari bencana dan malapetaka, maka harus melakukan aturan-aturan tersebut. Dengan demikian, mitos ini kemudian berubah menjadi ritus dan ritus menjadi simbol dan simbol menjadi norma yang berlaku dalam suatu masyarakat.

Kalau sudah menjadi norma, maka harus ditepati, jika tidak sanksinya adalah malapetaka dan dijauhi oleh masyarakat setempat di mana ia tinggal. Contoh-contoh seperti ini berlaku dalam masyarakat yang terbentuk didalamnya berbagai macam slametan, dengan berbagai macam pula simbolnya, misalnya nasi tumpeng dan seterusnya.

Dengan demikian, dipahami bahwa ritual mesambakay merupakan tradisi yang telah mengakar dalam kehidupan dan hingga kini masih ditaati, dipatuhi dan dilaksanakan oleh masyarakat komunitas adat TolakiMekongga. Fakta hasil observasi menunjukkan bahwa ritual mesambakay masih tetap dilakukan oleh masyarakat 
Mekongga, karena mereka menganggap suatu tradisi yang tidak dapat ditinggalkan dan sebagai warisan budaya yang ditransmisi dari generasi ke generasi.

Berdasarkan data di lapangan dapat diketahui bahwa mesambakay memiliki hubungan dengan proses sosial, di mana proses tersebut merupakan pemahaman dari simbol di dalam kehidupan komunitas adat TolakiMekongga sehingga keyakinan menjadi kebiasaan yang terus menerus dilakukan sebagai upaya mempertahankan budaya masyarakat khususnya bagi komunitas adat Tolaki-Mekongga.

Simbol di dalam kehidupan sosial masyarakat dipahami memiliki warna, bagaimana simbol dimaknai, dipahami, dan dikonsepsi berdasarkan keadaan sosial yang relevan terjadi di dalam kehidupan sosial masyarakat. Dalam hal ini, Victor Turner mengkaji konsep simbol di dalam keagamaan, dimana simbol-simbol yang di dalam keagamaan memuat doktrin-doktrin agama berubah bentuk menjadi serangkaian metaphor dan simbol untuk melihat cara masyarakat mempertahankan struktur sosialnya.

Di sisi lain, Geertz memandang konsep simbol sebagai sistem makna melalui kajian mengenai agama, mitos dan upacara keagamaan sebagai jalan untuk memahami dan menerima hakekat dari kehidupan sosial dimasyarakatnya. Adapun, Talal (1993) memandang simbol bukanlah benda atau peristiwa yang bertugas menyampaikan makna melainkan perangkat yang merangkaikan hubungan antara benda atau peristiwa merupakan suatu konsep yang memiliki makna.

Hal ini menunjukkan bahwa pelaksanaan mesambakay memiliki simbol yang mengandung sistem makna bagi kehidupan masyarakat khususnya pada masyarakat di Kabupaten Kolaka bahwa mesambakay merupakan tindakan simbolik yang menghadirkan klasifikasi simbolik dan konsep tindakan sosial yang mendorong proses modernisasi, artinya perkembangan teknologi ilmu pengetahuan tidak merubah tatanan masyarakat itu sendiri, justru keberadaan ilmu pengetahuan semakin meningkatkan dan menguatkan tradisi mesambakay ke arah perubahan modernisasi hingga saat ini.

\section{KESIMPULAN}

Berdasarkan pembahasan di atas dapat ditarik beberapa kesimpulan berikut. Proses pelaksanaan mesambakay pada komunitas adat Tolaki- Mekongga di Kabupaten Kolaka terdiri atas beberapa tahapan, yakni Membarakai (bahan/peralatan) Memberitahukan dan menyiapkan seluruh anggota keluarga yang akan mengikuti prosesi mesambakay; rombongan mbuakoy tiba di rumah; Mbuakoy mengambil bahan-bahan atau alat yang telah disiapkan; anak/bayi serta anak perempuan dewasa dipanggil masuk untuk dilakukan tradisi mesambakay; Mbuakoy membaca mantra langsung mowukui (komat kamit) terhadap anak bayi tersebut; Umo rapi (anak laki-laki yang bertugas berteriak) humohoria: aso, ruo, tolu, omba, 4 kali di ucapkan lalu kelur dari rumah tempat acara pesta setelah itu umo rapi masuk kembali ke dalam rumah; Mbuakoy lalu melanjutkan dan memanggil (mekaoee) kepada semua yang terlibat dalam prosesi adat mesambakay untuk mencicipi sesajian yang ada di wadah siwole; dan dilanjutkan dengan makan bersama dengan semua keluarga yang datang/hadir di pesta tersebut.

Makna simbolik mesambakay pada 
komunitas adat Tolaki-Mekongga di Kabupaten Kolaka menunjukkan adanya interaksi sesama manusia, interaksi dengan alam sekitar dan interaksi dengan Tuhan, sehingga makna itu terdapat dari beberapa simbol-simbol alat dan bahan yang digunakan dalam ritual mesambakay seperti bambu (kowuna), tempat makanan (siwole), ikat kepala (kinawo), daun-daunan (tawa), tempurung kelapa (ullo), dan sepasang ayam (omanu).

\section{DAFTAR PUSTAKA}

Anwar. (2009). Sejarah Daerah Kolaka. Bandung: Humaniora.

Geertz, C. (1992). Kebudayaan dan Agama, terj. Francisco Budi Hardiman. Yogyakarta: Kanisius.

Koentjaraningrat. (2009). Pengantar Ilmu Antropologi. Jakarta: PT Rineka Cipta.

Pos, K. (2010). Lima Suku di Sultra Ahirnya di Akui. Kendari:
Kendari Pos, Koran Media Cetak.

Spradley, J. P. (1997). Metode Etnografi. Yogyakarta: PT Tiara Wacana Yogya.

La Aso dan Taembo. (2016). Ritual Kasambu pada Etnik Muna di Kabupaten Muna, Provinsi Sulawesi Tenggara. Seminar Nasional Asosiasi Tradisi Lisan. Denpasar: Universitas Dwijendra Bali.

Talal, A. (1993). The Conctruction of religion as an Anthropology Category in The Genealogy of Religion: Disiplin and Reason of Power in Christyani and Islam. Johns Hopkins, University Press.

Wardiyanta. (2006). Metode Penelitian Pariwisata. Yogyakarta: ANDI.

Weber, M. (1957). The Mirror. New York: Lithograph. 